\title{
Genetic diversity and volatile oil components variation in Achillea fragrantissima wild accessions and their regenerated genotypes
}

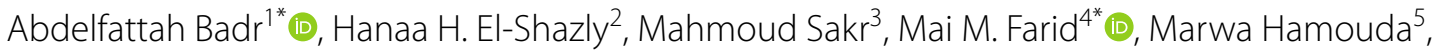 \\ Eman Elkhateeb ${ }^{5}$ and Hanan Syed Ahmad ${ }^{5}$
}

\begin{abstract}
Background: Wild medicinal plants are suffering natural environmental stresses and habitat destruction. The genetic diversity evaluation of wild accessions and their in vitro raised genotypes using molecular markers, as well as the estimation of substances of pharmaceutical value in wild plants and their regenerated genotypes are convenient approaches to test the genetic fidelity of regenerated plants as a source of substances of pharmaceutical value. In this study, the genetic diversity of 12 accessions of the medicinal plant Achillea fragrantissima, representing five sites in the mountains of South Sinai, Egypt, were estimated by the inter simple sequence repeats (ISSR) fingerprinting and their volatile oil components were identified using gas chromatography-mass spectrometry (GC-MS) analysis. The same accessions were regenerated in vitro and the genetic diversity and volatile oil components of propagated genotypes were determined and compared to their wild parents.
\end{abstract}

Results: Clustering and principal component analyses indicated that the wild accessions and their regenerated genotypes were genetically differentiated, but the regenerated plants are relatively more diverse compared to their wild parents. However, genetic variation between wild accessions is inherited to their in vitro propagated genotypes indicating genotypic differentiation of the examined accessions. The number of volatile oil compounds in the wild A. fragrantissima accessions was 31 compounds while in the in vitro propagated plants only 24 compounds were detected. Four major compounds are common to both wild and regenerated plants; these are artemisia ketone, alpha-thujone, dodecane, and piperitone.

Conclusions: Genome profiling and essential oil components analysis showed variations in A. fragrantissima accessions from different populations. Genetic differences between wild and regenerated genotypes were analyzed and validated with the final conclusion that in vitro conditions elicited higher genetic variation that is associated with reduced amount and diversity in the essential oil components.

Keywords: Achillea fragrantissima, Essential oil, Genetic diversity, In vitro regeneration

\footnotetext{
*Correspondence: abadr@science.helwan.edu.eg; mainscience2000@gmail. com

1 Botany and Microbiology Department, Faculty of Science, Helwan University, Cairo 117900, Egypt

${ }^{4}$ Department of Phytochemistry and Plant Systematics, National Research Centre, Cairo, Egypt

Full list of author information is available at the end of the article
}

\begin{abstract}
Background
Most medicinal plants, particularly in the arid environments, are decreasing in the wild due to weak regeneration under natural environmental stresses such as drought and salinity, and habitat destruction due to heavy overuse as well as overgrazing, uncontrolled collection,
\end{abstract}

Springer Open

(C) The Author(s) 2021. Open Access This article is licensed under a Creative Commons Attribution 4.0 International License, which permits use, sharing, adaptation, distribution and reproduction in any medium or format, as long as you give appropriate credit to the original author(s) and the source, provide a link to the Creative Commons licence, and indicate if changes were made. The images or other third party material in this article are included in the article's Creative Commons licence, unless indicated otherwise in a credit line to the material. If material is not included in the article's Creative Commons licence and your intended use is not permitted by statutory regulation or exceeds the permitted use, you will need to obtain permission directly from the copyright holder. To view a copy of this licence, visit http://creativecommons.org/licenses/by/4.0/. 
mining, and urbanization [1-3]. Therefore, conservation of wild medicinal plants using in vitro propagation is a vital approach to preserve their medicinal and pharmaceutical value. For this objective, it is important to evaluate the genetic variability in natural populations and also preserve genetic variability in the in vitro raised genotypes. The genetic diversity of wild and in vitro raised plants has been evaluated using genome profiling by using different molecular markers [3-5]. The genome profiling of plants with pharmaceutical value, using different molecular fingerprinting methods, was reviewed by Gantait et al. [6]. Several of these methods have been applied to address the genetic fidelity of in vitro propagated plants, examples include Hedychium coronarium by inter simple sequence repeats (ISSR) [7], the endangered medicinal plant Rauwolfia tetraphylla, by start codon targeted polymorphism (SCoT), ISSR, and random amplified polymorphic DNA (RAPD) [8], Helianthus verticillatus in vitro raised plants using SSRs [9] and the blackberry (Rubus fruticosus L.) using RAPD and sequence-related amplified polymorphism (SRAP) [10].

Plant regeneration by in vitro systems is generally associated with the presence of variations among regenerants $[11,12]$. These variations may be connected to epigenetic modifications occurring in an individual's genome that ultimately influence the organism's development and the process of its heredity $[13,14]$. In this connection, Zarreen et al. [15] reported 33\% and 25\% molecular polymorphism between wild type and in vitro regenerated Aloe Vera plantlets using RAPD and ISSR markers analysis respectively. The ISSRs and SSAP markers were able to detect soma-clonal variation in the callus of Artemisia absinthium, while no variation was detected in the plants regenerated from the nodal explants [16]. Few reports are available on the preservation of the chemical substances that have pharmaceutical value and the genetic diversity of regenerated genotypes. In Silybum marianum, growing in different geographic locations in Iran, RAPD markers were found associated with variation in the content of the major pharmaceutical substance, silymarin [17], and Thymus vulgaris clones were distinguished as five chemotypes using 12 ISSR primers [18].

A. fragrantissima is a very well-known medicinal plant [19]. It is a desert plant used in traditional medicine in the Arabian region for the treatment of various illnesses such as hepatobiliary disorders, skin inflammations, inflammatory disorders, hypoglycemia, diabetes lowering blood cholesterol levels, and as an appetite enhancing drug $[19,20]$. The essential oil extracted from $A$. fragrantissima exerts a bactericidal effect on Escherichia coli cells [21]; Candida albicans [22] and its extracts have antiviral activity against polio [23]. Phytochemicals present in the A. fragrantissima extract could be beneficial in preventing or treating neurodegenerative diseases [24] and for cancer prevention activity in the treatment of chronic myeloid leukemia cells [25]. The diversity among the populations of $A$. fragrantissima in Egypt based on morphological variation and ISSR marker profiling was previously evaluated by Badr et al. [26] and the genetic diversity and population structure of A. fragrantissima in South Sinai in Egypt was recently reported [27] and the essential oil components have been investigated in connection with their antimicrobial activity $[28,29]$ and components of aerial parts of plants from Egypt and Saudi Arabia were recently compared [30].

The objectives of the present study are to address genetic diversity as measured by ISSR fingerprinting polymorphism and variation in the chemical composition in A. fragrantissima wild accessions and their regenerated genotypes and to report for the first time the genetic fidelity of the in vitro regenerated plants and the correlation between the genetic diversity and chemical variation in wild plants and in-vitro derived plants.

\section{Methods \\ Plant collection and seed germination}

Twelve accessions of A. fragrantissima were collected, as individual plants were selected for the current study, from five sites in the mountains of South Sinai. The area, site, GPS location, number of samples, and elevation of localities from which the examined accessions are collected are given in Table 1. For each accession, ten key morphological traits were measured, and the values of their measurements are given in Table 2.

\section{In vitroregeneration of $A$. fragrantissima}

Seeds of all accessions were surface sterilized by immersion in $70 \%$ ethanol for $60 \mathrm{~s}$, and then rinsed in $20 \%$ $\mathrm{NaOCl}$ solution and drops of tween 20 for 20 min. Seeds were then washed three times with sterile distilled water and germinated on moist filter papers and basic MS mediums [31]. The percentage of germination on MS medium was much higher for all accessions (Table 1) and consequently, seedlings grown on MS medium were used for regeneration. For the initiation of regeneration, shoot explants of 1-month-old seedlings were cultured on full strength solidified basal MS medium supplemented with ( $0.5 \mathrm{mg} / \mathrm{l} \mathrm{BA}+0.5 \mathrm{mg} / \mathrm{l} \mathrm{NAA})$, which was the best media giving the highest number of shoots for most accessions after 1 month of incubation. Regenerated plants were acclimatized on soil containing Patmos and perlite in a ratio of 1:2 in small pots wrapped in a plastic bag and incubated under a photoperiod of $16 / 8 \mathrm{~h}$ light/ dark (Ca. $50 \mu \mathrm{mol} \mathrm{m}^{-2} \mathrm{~s}^{-1}$ ) at a constant temperature of $25 \pm 1^{\circ} \mathrm{C}$ for 2 months and then transferred to $15 \mathrm{~cm}$ diameter pot for acclimatization. 
Table 1 The area, site, GPS location, number of samples and elevation of localities from which the examined A. fragrantissima accessions were collected

\begin{tabular}{|c|c|c|c|c|c|c|}
\hline \multirow[t]{2}{*}{ Area } & \multirow[t]{2}{*}{ Population code } & \multirow[t]{2}{*}{ GPS location } & \multirow[t]{2}{*}{ Elevation } & \multirow[t]{2}{*}{ Sample Code } & \multicolumn{2}{|c|}{ Germination \% } \\
\hline & & & & & Paper & MS medium \\
\hline \multirow{5}{*}{$\begin{array}{l}\text { Wadi El-Arbaein } \\
\text { St. Catherine }\end{array}$} & \multirow[t]{5}{*}{ W 1} & \multirow{5}{*}{$\begin{array}{l}N: 28.55399^{\circ} \\
E: 033.9497^{\circ}\end{array}$} & \multirow[t]{5}{*}{$1583(\mathrm{~m})$} & W 1-1 & $64 \%$ & $78 \%$ \\
\hline & & & & W $1-2$ & $58 \%$ & $75 \%$ \\
\hline & & & & W 1-3 & $52 \%$ & $70 \%$ \\
\hline & & & & W 1-4 & $56 \%$ & $73 \%$ \\
\hline & & & & W $1-5$ & $42 \%$ & $65 \%$ \\
\hline \multirow[t]{3}{*}{ South Sinai, east of Saint-Catherine } & \multirow[t]{3}{*}{ W 2} & \multirow{3}{*}{$\begin{array}{l}N: 28.69700^{\circ} \\
E: 034.0408^{\circ}\end{array}$} & \multirow[t]{3}{*}{$1348(\mathrm{~m})$} & W 2-1 & $57 \%$ & $77 \%$ \\
\hline & & & & W 2-2 & $74 \%$ & $80 \%$ \\
\hline & & & & W 2-3 & $55 \%$ & $71 \%$ \\
\hline \multirow[t]{4}{*}{ South Sinai, west of Saint-Catherine } & \multirow[t]{2}{*}{ W3 } & \multirow{2}{*}{$\begin{array}{l}N: 28.64873^{\circ} \\
E: 033.89046^{\circ}\end{array}$} & \multirow[t]{2}{*}{$1104(\mathrm{~m})$} & W 3-1 & $64 \%$ & $66 \%$ \\
\hline & & & & W 3-2 & $68 \%$ & $70 \%$ \\
\hline & W 4 & $\begin{array}{l}N: 28.69000^{\circ} \\
E: 033.98115^{\circ}\end{array}$ & $1262(\mathrm{~m})$ & W 4-1 & $68 \%$ & $70 \%$ \\
\hline & W 5 & $\begin{array}{l}\mathrm{N}: 28.77283^{\circ} \\
\mathrm{E}: 034.17673^{\circ}\end{array}$ & $1072(\mathrm{~m})$ & W 5-1 & $58 \%$ & $75 \%$ \\
\hline
\end{tabular}

Table 2 Measurements of ten morphological traits for 12 samples of A. fragrantissima

\begin{tabular}{|c|c|c|c|c|c|c|c|c|c|c|}
\hline Plant code & Plant height & $\begin{array}{l}\text { Crown } \\
\text { diameter }\end{array}$ & Size index & $\begin{array}{l}\text { Height/ } \\
\text { diameter }\end{array}$ & $\begin{array}{l}\text { Leaf } \\
\text { length } \\
(\mathrm{cm})\end{array}$ & Leaf width $(\mathrm{cm})$ & $\begin{array}{l}\text { Head } \\
\text { length } \\
(\mathrm{cm})\end{array}$ & Head width (cm & $\begin{array}{l}\text { Bracts } \\
\text { length } \\
(\mathrm{mm})\end{array}$ & $\begin{array}{l}\text { Number } \\
\text { of florets/ } \\
\text { dead }\end{array}$ \\
\hline W 1-1 & 97 & 88 & 92.5 & 1.10 & 0.83 & 0.26 & 0.72 & 0.40 & 3.35 & 29 \\
\hline W 1-2 & 86 & 82 & 84.0 & 1.05 & 1.10 & 0.30 & 0.72 & 0.35 & 3.28 & 26 \\
\hline W 1-3 & 96 & 75 & 85.5 & 1.28 & 0.68 & 0.28 & 0.68 & 0.38 & 3.50 & 31 \\
\hline W 1-4 & 94 & 80 & 87.0 & 1.18 & 0.78 & 0.2 & 0.57 & 0.3 & 3.40 & 35 \\
\hline W 1-5 & 98 & 87 & 92.5 & 1.13 & 0.69 & 0.2 & 0.55 & 0.3 & 3.20 & 32 \\
\hline W 2-1 & 110 & 77 & 93.5 & 1.43 & 1.26 & 0.36 & 0.73 & 0.36 & 3.50 & 31 \\
\hline W 2-2 & 106 & 75 & 90.5 & 1.41 & 0.85 & 0.34 & 0.65 & 0.30 & 3.70 & 30 \\
\hline W 2-3 & 99 & 83 & 91.0 & 1.19 & 1.00 & 0.40 & 0.70 & 0.40 & 3.10 & 28 \\
\hline W 3-1 & 85 & 72 & 78.5 & 1.18 & 0.65 & 0.32 & 0.57 & 0.33 & 3.0 & 27 \\
\hline W 3-2 & 89 & 76 & 82.5 & 1.17 & 0.62 & 0.29 & 0.60 & 0.40 & 3.0 & 29 \\
\hline W 4-1 & 87 & 97 & 92.0 & 1.13 & 0.74 & 0.31 & 0.5 & 0.37 & 3.32 & 33 \\
\hline W 5-1 & 97 & 97 & 97.0 & 1.0 & 1.16 & 0.36 & 0.73 & 0.36 & 3.50 & 33 \\
\hline
\end{tabular}

\section{Methods of essential oil analysis}

Fresh shoot parts of mature wild $A$. fragrantissima accessions were air-dried in shade at room temperature until constant weight. The dried material was grounded with a blender to a fine powder and stored at $4^{\circ} \mathrm{C}$ in a tightly covered bottle. For regenerated genotypes, vegetative parts of acclimatized plants were also dried at room temperature to a constant weight, powdered in a blender, and stored at $4{ }^{\circ} \mathrm{C}$ in a tightly covered bottle. For essential oil extraction, $100 \mathrm{gm}$ of the powdered material was distilled in a modified Clevenger apparatus using distilled water for approximately $3 \mathrm{~h}$. The oil prepared in each case passed over anhydrous sodium sulfate to be dried and was stored at $-20^{\circ} \mathrm{C}$ until further analysis. The extracted oil was dehydrated over anhydrous sodium sulfate and kept in the refrigerator until used for the gas chromatography-mass spectrometry (GC-MS) analysis. The GC-MS analysis was carried out at the Department of Medicinal and Aromatic Plants Research, National Research Center with the following specification using a TRACE GC Ultra Gas Chromatographs (THERMO Scientific Corp., USA), coupled with a THERMO mass spectrometer detector (ISQ Single Quadrupole Mass Spectrometer). The GC-MS system was equipped with a TR-5 MS column (30 $\mathrm{m} \times 0.30 \mathrm{~mm}$ i.d., $0.25 \mu \mathrm{m}$ film thickness). Analyses 
were carried out using helium as carrier gas at a flow rate of $1.0 \mathrm{~mL} / \mathrm{min}$ and a split ratio of 1:10 using the following temperature program: $60^{\circ} \mathrm{C}$ for $1 \mathrm{~min}$; rising at $3.0^{\circ} \mathrm{C} / \mathrm{min}$ to $240^{\circ} \mathrm{C}$ and held for $1 \mathrm{~min}$. The injector and detector were held at $300^{\circ} \mathrm{C}$. Diluted samples $(1: 10$ hexane, $\mathrm{v} / \mathrm{v}$ ) of $0.2 \mu \mathrm{L}$ of the mixtures were always injected. Mass spectra were obtained by electron ionization (EI) at $70 \mathrm{eV}$, using a spectral range of $m / z 40-450$.

\section{ISSR fingerprinting}

DNA extraction and PCR procedures for the ISSR fingerprinting were performed as described by Badr et al. [26] using the properties and sequence of the primer listed in Table 3. The ISSR markers for wild accessions and their regenerated plants were visualized and the size of each marker was estimated and scored as either present or absent in a data matrix and used for calculating the genetic diversity and also for calculating the correlation between ISSR polymorphism and variation in essential oil components in wild accessions and regenerated plants.

\section{Data analyses}

The number of ISSR amplified alleles including, polymorphic alleles, unique alleles, and the percentage of polymorphism revealed by each primer, in the examined wild and regenerated plants of the examined sites are given in Table 3. In scoring ISSR fingerprinting, polymorphic markers refer to alleles found in at least two samples, and a unique allele is found in one sample whereas monomorphic markers are found in all samples, the latter markers did not differentiate samples from each other.

Genetic diversity among the 12 individual wild accessions and their regenerated genotypes was calculated based on the binary data from the amplified ISSRs alleles using the Community Analysis Package-5 (CAP) by Seaby and Henderson [32], and an average linkage tree based on hierarchical grouping function [33] was constructed. The PAST (Paleontological Statistics) software [34] was also used to construct a tree, based on the Euclidean distance using the Unweighted Pair Group Method with Arithmetic Mean (UPGMA). A scatter plot of the examined plant accessions was also made using the principal coordinates analysis

Table 3 Primers codes, sequences ( $Y=C$ or $T$ ) as well as the total number of amplified alleles (total), polymorphic alleles (polym), monomorphic alleles (mono) unique alleles (unique) and \% of total polymorphism induced in wild and regenerated accessions of $A$. fragrantissima

\begin{tabular}{|c|c|c|c|c|c|c|c|c|c|}
\hline \multirow[t]{2}{*}{ Primer } & \multirow[t]{2}{*}{ Sequence (5-3) } & \multicolumn{4}{|c|}{ Number of amplified alleles in wild accessions } & \multicolumn{4}{|c|}{$\begin{array}{l}\text { Number of amplified alleles in regenerated } \\
\text { accessions }\end{array}$} \\
\hline & & Total & Polym & Mono & Unique & Total & Polym & Mono & Unique \\
\hline 807 & $(A G) 8 T$ & 5 & 3 & 1 & 1 & 6 & 5 & 1 & 0 \\
\hline 809 & $(A G) 8 G$ & 5 & 4 & 1 & 0 & 6 & 3 & 2 & 1 \\
\hline 814 & (CT)8 TC & 5 & 3 & 1 & 1 & 7 & 6 & 1 & 0 \\
\hline 825 & $(\mathrm{AC}) 8 \mathrm{~T}$ & 4 & 2 & 1 & 1 & 5 & 4 & 1 & 0 \\
\hline 834 & $(\mathrm{AC}) 8 \mathrm{YT}$ & 6 & 5 & 1 & 0 & 6 & 5 & 1 & 0 \\
\hline 841 & $(G A) 8 Y C$ & 5 & 4 & 1 & 0 & 6 & 5 & 1 & 0 \\
\hline $844-B$ & $(\mathrm{CT}) 8 \mathrm{GC}$ & 6 & 4 & 1 & 1 & 6 & 3 & 2 & 1 \\
\hline $17898-B$ & (CA)6 GT & 9 & 7 & 1 & 1 & 9 & 5 & 3 & 1 \\
\hline 17899-A & $(C A) 6 A C$ & 5 & 4 & 1 & 0 & 5 & 5 & 0 & 0 \\
\hline 17899-B & $(C A) 6 \mathrm{GG}$ & 5 & 3 & 2 & 0 & 7 & 5 & 2 & 0 \\
\hline HB-08 & $(G A) 6 G G$ & 5 & 4 & 1 & 0 & 7 & 5 & 2 & 0 \\
\hline HB-09 & $(\mathrm{GT}) 6 \mathrm{GG}$ & 8 & 6 & 1 & 1 & 8 & 6 & 2 & 0 \\
\hline HB-10 & $(G A) 6 C G$ & 7 & 6 & 1 & 0 & 7 & 5 & 2 & 0 \\
\hline HB-11 & $(\mathrm{GT}) 6 \mathrm{CG}$ & 7 & 6 & 1 & 0 & 7 & 5 & 2 & 0 \\
\hline HB-12 & $(\mathrm{CAC}) 3 \mathrm{GC}$ & 8 & 7 & 1 & 0 & 8 & 6 & 2 & 0 \\
\hline HB-13 & $(G A G) 3 G C$ & 7 & 5 & 1 & 1 & 7 & 4 & 2 & 1 \\
\hline HB-14 & (CTC)3 GC & 6 & 5 & 1 & 0 & 6 & 4 & 2 & 0 \\
\hline HB-15 & (GTG)3 GC & 5 & 4 & 1 & 0 & 5 & 4 & 1 & 0 \\
\hline UBC-820 & $(\mathrm{GT}) 8 \mathrm{C}$ & 6 & 5 & 1 & 0 & & & & \\
\hline UBC-827 & $(\mathrm{AC}) 8 \mathrm{G}$ & 4 & 3 & 1 & 0 & & & & \\
\hline Total & & 118 & 90 & 21 & 7 & 118 & 85 & 29 & 4 \\
\hline Percentage & & & 76.27 & 17.8 & 5.93 & & 72.03 & 24.58 & 3.6 \\
\hline
\end{tabular}


(PCA) in the PAST software to illustrate the grouping of the 24 A. fragrantissima plant samples including the 12 wild accessions and the regenerated plants based on variation in the polymorphism in the ISSR alleles.

The pheatmap and ggplot2 packages [35, 36] were used to visualize the similarity of wild accessions and their in vitro regenerated genotypes based on the variation in volatile oil components. A correlation matrix was created using the proportions of components by MrBayes [37]. The "actoextra" package of Kassambara and Mundt [38] was also used to extract and visualize the results of multivariate data analyses to produce a heatmap. In the heatmap, the scale of color is relative to the value of the divergence between investigated values. Pearson correlation values between the morphological and the chemical composition for the 12 wild accessions of A. fragrantissima were calculated using two variables by the R-software package, and the correlation coefficients were expressed as complot [39]. Meanwhile, Pearson correlation coefficients correlation values between volatile oils constituents and the ISSR alleles for the wild accessions and the regenerated genotypes were calculated using the IBM SPSS Statistics Analysis Package.

\section{Results}

\section{The ISSR fingerprinting}

The results of the ISSR fingerprinting of the examined 12 wild individual accessions of $A$. fragrantissima from the five sites using 20 ISSR primers and their in vitro regenerated genotypes using 18 primers, are summarized in Table 3. A total of 118 ISSR bands (alleles) were amplified in all wild plants using the 20 primers and the same number was recorded in the regenerated plants using 18 primers. Figure 1 illustrates examples of ISSR fingerprints amplified in the 12 regenerated plants by the primers 807 (A), pr. 809 (B), pr. 814 (C), pr.17898 (D). pr. 825 (E) and pr. UBC 820 (F), respectively. A 100 bp ladder was used to indicate the molecular size of markers that ranged in size between $100 \mathrm{bp}$ and $700 \mathrm{bp}$. The highest number of alleles (9 bands) were produced by 17898 -B in wild plants and regenerated plants and the lowest number of alleles was produced by primer 825 in the wild plants. The percentage of polymorphism in wild plants is $76.27 \%$ and in the regenerated plants is 72.03. The number and percentage of monomorphic markers (alleles) are lower in wild plants compared to regenerated genotypes, whereas the number and percentage of unique alleles are higher in the regenerated plants compared to wild plants (Table 3 ).
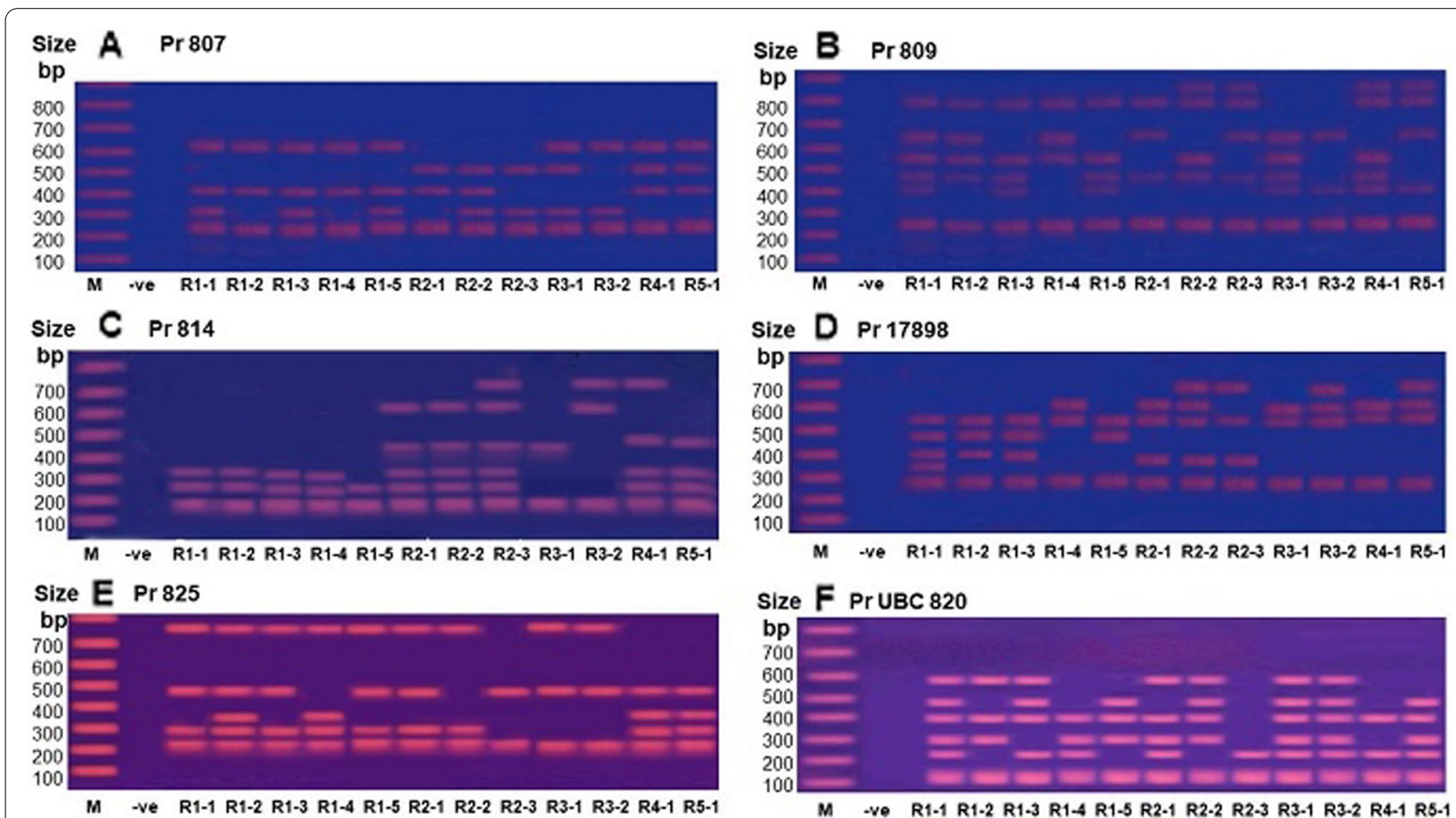

Fig. 1 Photographs illustrating the ISSR fingerprinting of the 12 regenerated genotypes of A. fragrantissima, induced by the six primers. A pr $807, \mathbf{B}$ pr 809, C pr 814, D pr. 17898, E pr 825, and F pr UPC 820 


\section{Genetic diversity among wild accessions and regenerated genotypes}

The genetic diversity among wild accessions and their regenerated plants expressed as a CAP average linkage tree based on hierarchical grouping function is illustrated in Fig. 2. Ten wild accessions representing site 1 (W 1-1, W 1-2, W 1-3 W 1-4, W 1-5), site 2 (W 2-1, W 2-2, W 2-3), and site 3 (W 3-1, W 3-2) are differentiated as a major group from the other two wild accessions from the two sites W 4-1 and W 5-1 and their regenerated plants which constitute another larger group of 14 samples. In the latter group, the two wild accessions $\mathrm{W}$ 4-1 and W 5-1 and their regenerated plants are grouped as a cluster comprising these four samples and the other two clusters, one comprising the five regenerated genotypes of site 1 (R 1-1, R 1-2, R 1-3 R 1-4, R 1-5), and the other comprises regenerated plants of the accessions of site 2 ( R 2-1, R 2-2, R 2-3) and site 3 (R3-1, R 3-2). On the other hand, the Euclidean distance UPGMA tree constructed using the PAST software (Fig. 3); differentiated all wild accessions from their regenerated plants as two different groups. In each group, the five plants representing site 1 , the three plants representing site 2 , and the two plants of site 3 are distinguished as three clusters from the two samples representing site 4 and site 5 respectively.

\section{Euclidean Distance -UPGMA Hierarchical clustering}

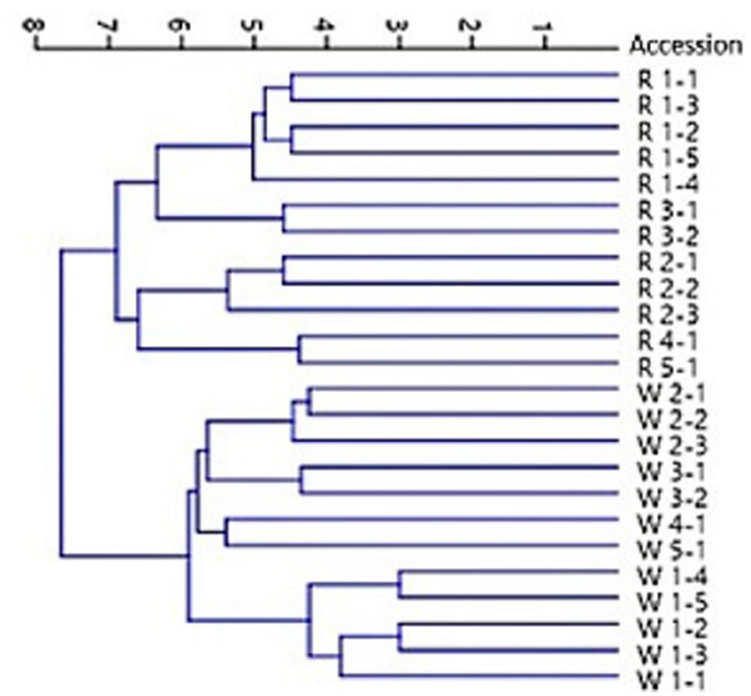

Fig. 3 Euclidean UPGMA distance tree constructed using the PAST software differentiating all wild accessions from their regenerated plants

The genetic differentiation of the wild accessions from their regenerated genotypes, based on the ISSR polymorphism is confirmed by a PCA scatter diagram, illustrating the grouping of the wild accessions and regenerated

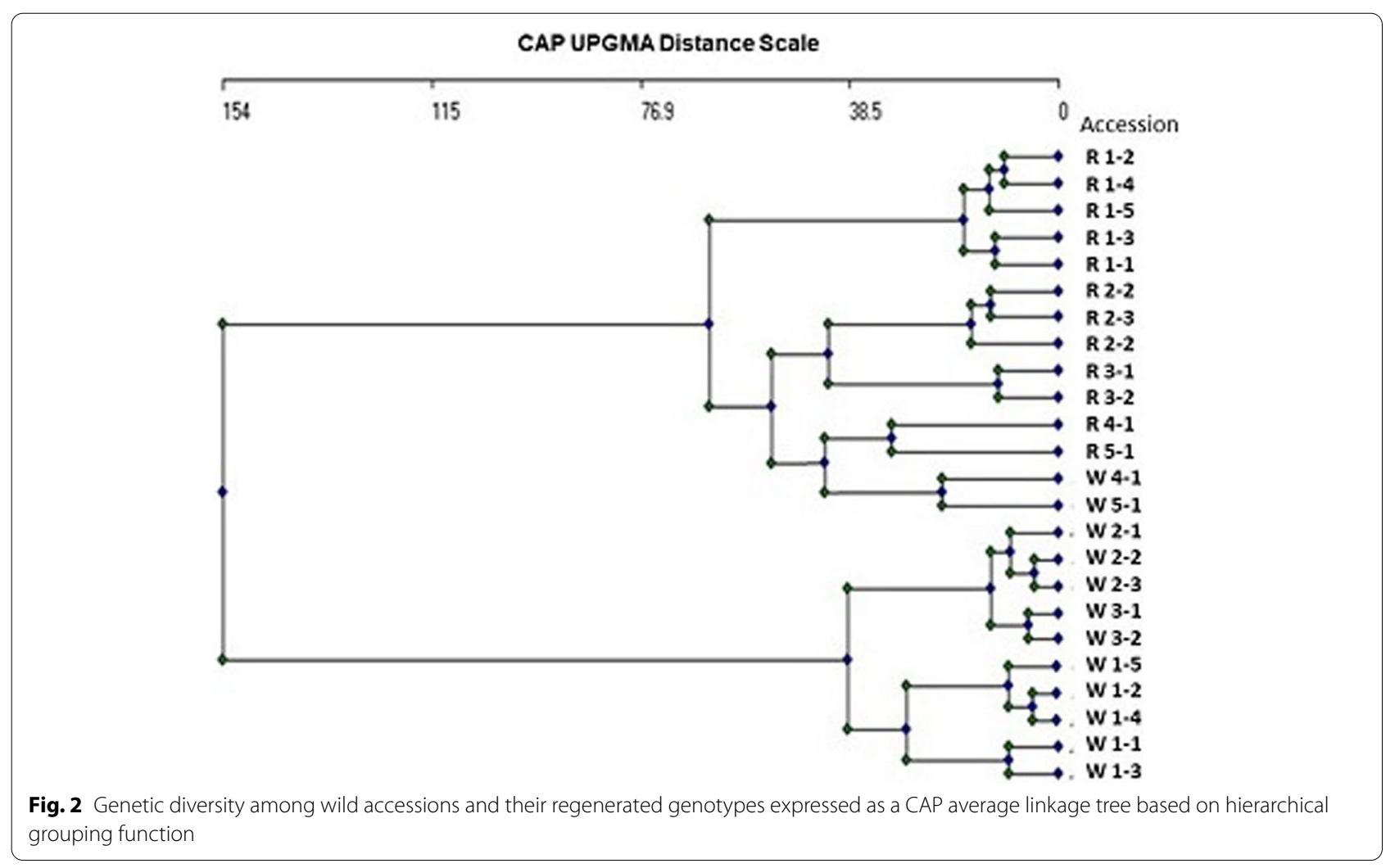


plants as two distinct groups (Fig. 4) which shows that regenerants from one population are closer to each other compared to accessions from different populations. In this diagram, the wild accessions are more closely related to each other whereas the regenerated genotypes are differentiated from each other. In addition, the genotypes regenerated from the same site are closer to each other compared to genotypes of different sites, this indicates that the genetic variation between wild accessions is inherited from their in vitro propagated genotypes.

\section{Essential oil constituents of wild and regenerated plants of $A$. fragrantissima}

The extracted liquid oil ranged in color from pale yellow oil to yellow with a strong penetrating pleasant odor. The amount of essential oil in the wild A. fragrantissima accessions was much higher compared to the regenerated plants (Tables 4 and 5). Its percentage in wild accessions ranges from $1.02 \%$ in the accession W3-1 to $2.18 \%$ in W1-3. However, it varies within accessions of sites 1 , 2 , and 3 . In the regenerated genotypes, the amount of essential oil ranges from $0.28 \%$ in R3-1 to $0.68 \%$ in R4-1. The chemical constituents of the essential oil in A. fragrantissima analyzed by GC-MS resulted in the identification of 31 compounds in the oil of the wild accessions (Table 4) and 24 compounds in the regenerated plants (Table 5). Gas chromatography-mass spectrometry (GCMS) total chromatogram for the volatile oil of two wild accessions and their regenerated genotypes are illustrated in Figs. 5 and 6, respectively. Four major compounds are common to both wild and regenerated plants; these are artemisia ketone, alpha-thujone, dodecane, and piperitone. The artemisia ketone, was a major compound in all accessions, in the wild accessions, it ranges between $17.6 \%$ in W1-1 and $10.5 \%$ in W4-1. In the regenerated genotypes, artemisia ketone was also a major compound in all genotypes; it ranged from $16.2 \%$ in RP1-3 to $9.11 \%$ in RP2-1. The piperitone amount ranges between $13.48 \%$ in W1-4 to $7.23 \%$ in W2-3 of the wild accessions. In the regenerated genotypes, piperitone ranged between $16.36 \%$ in RP5 to $8.48 \%$ in RP1-2. Meanwhile, alpha-thujone proportion ranged between $22.9 \%$ in W5.1 to $12.1 \%$ in W1.3. In the regenerated genotypes, the proportion of alpha-thujone ranged between $19.3 \%$ in R4.1 to $14.2 \%$ in R1.3. Dodecane was also a major compound in the wild and in vitro regenerated plants, but its proportion was higher in the regenerated genotypes, it ranged from 9.2\% in W5.1 to $3.3 \%$ in W1.5 of the wild accessions (Table 4) and from $17.2 \%$ in RP3.2 to $8.6 \%$ in RP1.3 of the regenerated genotypes (Table 5).

Santolina alcohol and p-menthane-3,8-diol,cis1,3, trans-1,4 were two major compounds in the wild accessions and were not recorded in the regenerated genotypes. The occurrence of both compounds showed no preference to particular sites but santolina alcohol was higher in W1-5 compared to other sites (Table 4). On the other hand, 1-borneol, sabinyl acetate, and camphor are more common to

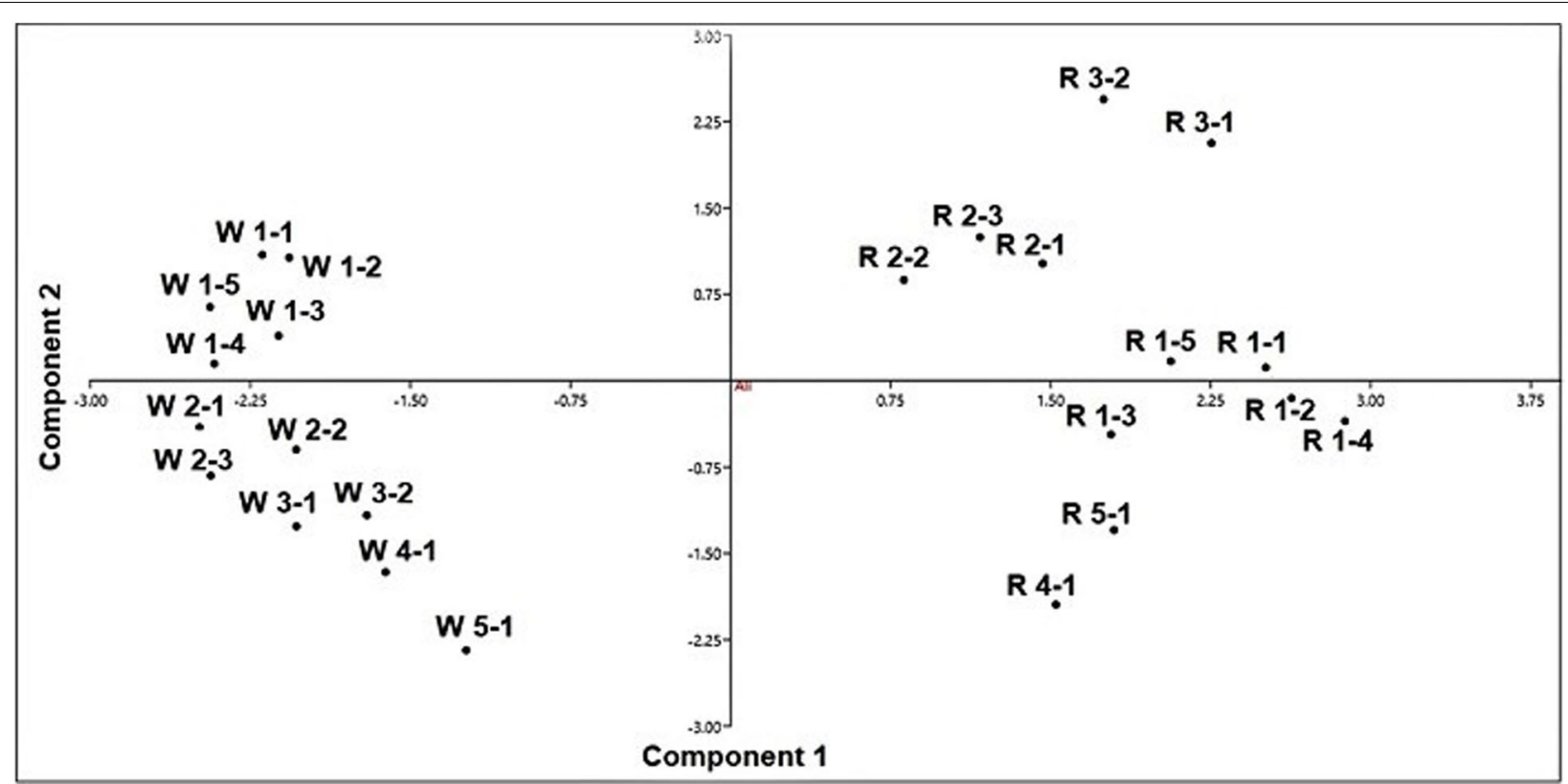

Fig. 4 PCA scatter diagram illustrating the separation of the wild accessions from their regenerated genotypes, as two distinct groups and the differentiation of regenerated genotypes 
Table 4 Retention time and components name and percentage of each component in the essential oil extracted from 12 individual plants representing five populations of $A$. fragrantissima

\begin{tabular}{|c|c|c|c|c|c|c|c|c|c|c|c|c|c|c|}
\hline Ser & RT & Components name & W1-1 & W1-2 & W1-3 & $W 1-4$ & W1-5 & W2-1 & W2-2 & W2-3 & W3-1 & W3-2 & W4-1 & W5-1 \\
\hline & & Total essential oil \% & 1.22 & 1.24 & 2.18 & 1.56 & 1.65 & 1.33 & 1.13 & 1.30 & 1.02 & 1.51 & 2.04 & 1.45 \\
\hline 1 & 5.55 & Santolina triene & 3.35 & 3.02 & 3.95 & 2.89 & 2.91 & 3.9 & 3.57 & 3.24 & 3.13 & 2.52 & 1.38 & 1.62 \\
\hline 2 & 6.56 & Sabinene & 0 & 0.8 & 0.23 & 0.45 & 0 & 0 & 0 & 0.33 & 0.23 & 0 & 0 & 0 \\
\hline 3 & 7.20 & Camphene & 2.64 & 2.95 & 2.78 & 2.64 & 4.75 & 4.64 & 4.68 & 5.44 & 4.57 & 3.64 & 1.64 & 1.51 \\
\hline 4 & 8.16 & o-Cymene & 0.19 & 1.4 & 0.26 & 0.77 & 0 & 0 & 0.39 & 0.55 & 0.46 & 0.51 & 0.69 & 0.42 \\
\hline 5 & 8.66 & $\begin{array}{l}\text { p-Menthane- } \\
\text { 3,8-diol,cis-1,3,trans-1,4- }\end{array}$ & 5.8 & 6.1 & 6.6 & 7.2 & 6.2 & 6.11 & 7.14 & 8.1 & 6.2 & 9.2 & 8.8 & 8.8 \\
\hline 6 & 9.08 & Santolina alcohol & 14.6 & 13.2 & 14.2 & 10.5 & 17.1 & 11.3 & 10.6 & 10.7 & 8.1 & 6.62 & 8.22 & 11.3 \\
\hline 7 & 9.65 & Eucalyptol & 0.66 & 1.14 & 0.89 & 1.56 & 1.45 & 1.43 & 1.6 & 1.39 & 1.02 & 0.96 & 7.86 & 0.23 \\
\hline 8 & 10.60 & Artemisia ketone & 17.6 & 16 & 15.2 & 14.4 & 15 & 13.1 & 13.23 & 11.5 & 11.5 & 11.36 & 10.5 & 13 \\
\hline 9 & 10.91 & Hotrienol & 0.82 & 0.78 & 0.85 & 0.78 & 0.69 & 0.81 & 0.83 & 1.3 & 0.79 & 0.64 & 0.77 & 1.07 \\
\hline 10 & 11.15 & Artemisia alcohol & 4.27 & 4.26 & 4.75 & 3.01 & 3.87 & 4.43 & 3.8 & 3.72 & 4.76 & 4.6 & 5.72 & 4.42 \\
\hline 11 & 11.72 & $\beta$-thujone & 1.8 & 2.27 & 3.26 & 3.01 & 3.67 & 2.85 & 3.6 & 3.73 & 4.76 & 4.74 & 0.44 & 0.42 \\
\hline 12 & 12.18 & alfa thujone & 15.6 & 16.39 & 12.1 & 15.7 & 15.81 & 20.1 & 20.4 & 19.5 & 20.3 & 19.5 & 21.75 & 22.9 \\
\hline 13 & 13.07 & Isopinocarveol & 0.57 & 2.6 & 0.4 & 0.03 & 0.41 & 0.82 & 0.54 & 0.67 & 0 & 1.84 & 2.41 & 2.86 \\
\hline 14 & 13.54 & Camphor & 0.16 & 0.42 & 0.18 & 0.08 & 0.23 & 0.06 & 0.28 & 0.11 & 0.27 & 0.17 & 0,21 & 0.23 \\
\hline 15 & 13.87 & 2-Methyl-2-octen-4-ol & 2.93 & 2.04 & 2.08 & 3.22 & 1.78 & 1.77 & 1.86 & 0.5 & 5.57 & 6.5 & 3.23 & 3.29 \\
\hline 16 & 14.01 & $( \pm)$-Lavandulol & 0.83 & 0.67 & 1.16 & 0.74 & 1.81 & 1.31 & 0.24 & 1.07 & 0.8 & 0.38 & 0.48 & 0.57 \\
\hline 17 & 14.88 & Terpinenene-4-ol & 0.61 & 0.44 & 0.67 & 1.13 & 0.63 & 0.86 & 0.35 & 0.19 & 0.69 & 0.58 & 0.72 & 0.8 \\
\hline 18 & 15.41 & Dodecane & 4.4 & 4.66 & 4.2 & 4.9 & 3.3 & 5.8 & 6.2 & 6.2 & 6.7 & 7.3 & 83 & 9.2 \\
\hline 19 & 15.60 & a-Terpineol & 0.18 & 0.41 & 0.17 & 0 & 0 & 0 & 0 & 0.62 & 0.17 & 0.15 & 0.62 & 0 \\
\hline 20 & 17.46 & 4a-ydroxyachipendol & 0.29 & 0 & 0.34 & 0.46 & 0.24 & 0.59 & 0.28 & 0.51 & 0.26 & 0.34 & 0.27 & 0.52 \\
\hline 21 & 19.35 & Lavandulyl acetate & 1.4 & 0.78 & 0.68 & 1.04 & 1.4 & 0.13 & 1.21 & 0.66 & 0.66 & 0.85 & 0.9 & 0.93 \\
\hline 22 & 19.71 & Sabinyl acetate & 0.78 & 1.2 & 0.3 & 3.2 & 0.71 & 2.58 & 3.72 & 5.34 & 1.4 & 1.38 & 2.42 & 2.42 \\
\hline 23 & 19.97 & Piperitone & 13.48 & 12.79 & 13.47 & 13.62 & 12.34 & 8.57 & 7.42 & 7.23 & 9.63 & 9.21 & 9.39 & 8.39 \\
\hline 24 & 20.05 & p-Cymen-7-ol & 0 & 0.56 & 0 & 0.43 & 0 & 0 & 0 & 0 & 0 & 0 & 0.22 & 0 \\
\hline 25 & 24.49 & cis-Jasmone & 0.44 & 0 & 0.13 & 0.43 & 0.54 & 0.55 & 0.34 & 0.46 & 0.26 & 0 & 0.24 & 0.27 \\
\hline 26 & 27.88 & Ethyl cinnamate & 3.35 & 3.02 & 3.95 & 2.89 & 2.51 & 3.9 & 3.17 & 2.24 & 3.13 & 3.52 & 1.38 & 3.62 \\
\hline 27 & 28.00 & Germacrene-d & 0 & 0.8 & 0.23 & 0.45 & 0 & 0 & 0 & 0.33 & 0.23 & 0 & 0 & 0 \\
\hline 28 & 28.63 & bicyclogermacrene & 0.64 & 0.65 & 1.18 & 1.64 & 1.75 & 3.64 & 3.46 & 2.64 & 2.07 & 1.64 & 1.64 & 1.51 \\
\hline 29 & 32.14 & (+) spathulenol & 0.59 & 0.4 & 0.26 & 0.77 & 0 & 0 & 0.39 & 0.55 & 0.46 & 0.51 & 0.29 & 0.42 \\
\hline 30 & 34.08 & Elemol & 0.8 & 1.3 & 0.6 & 0.7 & 0.2 & 0.1 & 0.1 & 0.5 & 0.9 & 0.2 & 0.8 & 0.8 \\
\hline \multirow[t]{2}{*}{31} & 35.35 & $\beta$-Eudesmol & 0.66 & 1.14 & 0.89 & 1.16 & 0.45 & 0.43 & 0.6 & 0.39 & 1.02 & 0.96 & 0.86 & 0.23 \\
\hline & & Total percentage & 99.28 & 99.12 & 99.78 & 99.72 & 99.75 & 99.78 & 99.72 & 99.6 & 99.77 & 99.65 & 99.94 & 99.52 \\
\hline
\end{tabular}

regenerated genotypes but at lower proportions compared to the other major compounds, although 1 -borneol was recorded at higher proportions in the regenerated plants of site 2 compared to other sites (Table 5). The proportion of these compounds varies between plants collected from different sites. Other four compounds, santolina triene, 2-methyl-2octen-4-ol,4-, $\alpha$-thujone, and ethyl cinnamate were represented in proportions ranging between $1 \%$ and $5 \%$ in the wild accessions. In total, the hydrocarbons constitute a small proportion of the oil while oxygenated constituents form the majority of the essential oil components.
Diversity of wild accessions and regenerated genotypes based on essential oil constituents

The proportions of the chemical constituents of the essential oil were used to measure the relatedness of the wild accessions and regenerated genotypes using the pheatmap and ggplot2 packages to produce the heatmap illustrated in Fig. 7. In this heatmap, the scale of color is relative to the value of the divergence between accessions. A glimpse on the heatmap shows that the wild accessions and regenerated plants are distinguished as two separate groups. The high similarity among accessions of each group is indicated by the dominance of the red color in the part of the heatmap representing the 
Table 5 Retention time and components name and percentage of each compound in the essential oil extracted from 12 regenerated plants representing 12 individual samples of six populations of A. fragrantissima

\begin{tabular}{|c|c|c|c|c|c|c|c|c|c|c|c|c|c|c|}
\hline Ser & RT & Components name & R1-2 & R1-2 & R1-3 & R1-4 & R1-5 & R2-1 & R2-2 & $\mathrm{R} 2-3$ & R3-1 & R3-2 & R4-1 & R5-1 \\
\hline & & Total essential oil \% & 0.55 & 042 & 0.66 & 0.64 & 0.65 & 0.38 & 0.44 & 0.57 & 0.28 & 0.53 & 0.68 & 0.48 \\
\hline 1 & 4.55 & Hexane & 1.57 & 2.35 & 3.02 & 2.83 & 2.91 & 2.42 & 2.52 & 3.14 & 3.13 & 2.75 & 1.58 & 3.62 \\
\hline 2 & 6.56 & Sabinene & 0 & 0.8 & 0.23 & 0.45 & 0 & 0 & 0 & 0.33 & 0.23 & 0 & 0 & 0 \\
\hline 3 & 7.20 & Limonene & 13 & 13.8 & 15.2 & 16.9 & 15.2 & 12.6 & 11.3 & 13.27 & 14.8 & 17.7 & 7.73 & 6.44 \\
\hline 4 & 8.36 & o-Cymene & 0.39 & 0.19 & 1.4 & 0.77 & 0 & 0.32 & 0.51 & 0.55 & 0.46 & 0.26 & 0.69 & 0.42 \\
\hline 5 & 8.56 & Camphene & 3.3 & 2.78 & 2.88 & 2.79 & 2.21 & 1.86 & 1.93 & 1.36 & 2.77 & 0.75 & 2.21 & 1.8 \\
\hline 6 & 8.65 & Eucalyptol & 0.6 & 0.66 & 4.14 & 1.56 & 0.45 & 3.09 & 5.96 & 6.39 & 1.02 & 0.89 & 1.86 & 0.23 \\
\hline 7 & 9.91 & Hotrienol & 0.83 & 0.82 & 0.78 & 0.78 & 0.69 & 0.82 & 0.64 & 1.03 & 0.79 & 0.85 & 0.77 & 1.07 \\
\hline 8 & 10.58 & Artemisia ketone & 16.2 & 14.6 & 17.0 & 16.4 & 10.02 & 9.11 & 9.3 & $10 . .0$ & 13.5 & 14.2 & 14.5 & 15.0 \\
\hline 9 & 11.18 & Artemisia alcohol & 4.8 & 4.27 & 2.26 & 5.01 & 3.87 & 2.85 & 3.6 & 3.7 & 2.76 & 3.75 & 4.72 & 4.42 \\
\hline 10 & 12.16 & alpha thujone & 16 & 14.66 & 14.2 & 14.9 & 15.3 & 15.8 & 162 & 16.2 & 18.7 & 18.3 & 19.3 & 18.2 \\
\hline 11 & 13.54 & Camphor & 2.86 & 3.93 & 1.04 & 2.22 & 3.78 & 4.32 & 1.5 & 0.5 & 1.57 & 2.08 & 3.23 & 3.29 \\
\hline 12 & 14.01 & $( \pm)$-Lavandulol & 0.24 & 0.83 & 0.67 & 0.74 & 1.81 & 1.17 & 0.38 & 1.07 & 0.8 & 1.16 & 0 & 0 \\
\hline 13 & 14.88 & Terpinene-4-ol & 0.35 & 0.61 & 1.44 & 1.13 & 0.63 & 1.14 & 0.58 & 1.39 & 0.69 & 0.67 & 0.72 & 0.8 \\
\hline 14 & 15.41 & Dodecane & 10.2 & 10 & 8.6 & 9.9 & 11.3 & 12.8 & 13.3 & 13.2 & 14.3 & 17.2 & 10 & 10.2 \\
\hline 15 & 15.60 & a-Terpineol & 0 & 0.18 & 0 & 0 & 0.41 & 0.4 & 0.15 & 0.62 & 0 & 0.17 & 0.62 & 0 \\
\hline 16 & 19.35 & 1-Borneol & 5.87 & 6.6 & 5.39 & 6.7 & 5.8 & 12.8 & 13.5 & 12.5 & 5.3 & 5.1 & 5.75 & 5.59 \\
\hline 17 & 19.69 & Sabinyl acetate & 9.72 & 8.8 & 7.2 & 10.2 & 10.4 & 5.4 & 6.8 & 7.34 & 5.3 & 4.3 & 9.42 & 10.42 \\
\hline 18 & 19.81 & Piperitone & 9.42 & 8.48 & 8.79 & 9.6 & 9.34 & 10.4 & 9.21 & 11.23 & 10.47 & 9.17 & 12.39 & 16.36 \\
\hline 19 & 20.05 & p-Cymen-7-ol & 0 & 0.56 & 0 & 0.43 & 0 & 0 & 0 & 0 & 0 & 0 & 0.22 & 0 \\
\hline 20 & 24.49 & cis -Jasmone & 0.34 & 0.44 & 0.56 & 0.83 & 0.54 & 0.19 & 0 & 0 & 0.26 & 0.13 & 0.04 & 0.27 \\
\hline 21 & 27.88 & Bicyclogermacrene & 2.32 & 2.7 & 2.12 & 2.22 & 3.3 & 2.18 & 1.58 & 4.3 & 2.2 & 0.3 & 3.72 & 6.4 \\
\hline 22 & 28.00 & Germacrene-d & 0 & 0.8 & 0.23 & 0.45 & 0 & 0 & 0 & 0.33 & 0.23 & 0 & 0 & 0 \\
\hline 23 & 34.08 & Dotriacontane & 1.49 & 0.79 & 1.46 & 1.57 & 1.39 & 0 & 0.9 & 0.64 & 0.43 & 0.19 & 0 & 1.01 \\
\hline \multirow[t]{2}{*}{24} & 35.35 & Elemol & 0 & 0 & 0 & 0 & 0 & 0 & 0.14 & 0.3 & 0.23 & 0 & 0.32 & 0.21 \\
\hline & & Total percentage & 99.5 & 99.65 & 99.61 & 98.78 & 99.35 & 99.67 & 100 & 99.39 & 99.94 & 99.92 & 99.79 & 99.78 \\
\hline
\end{tabular}
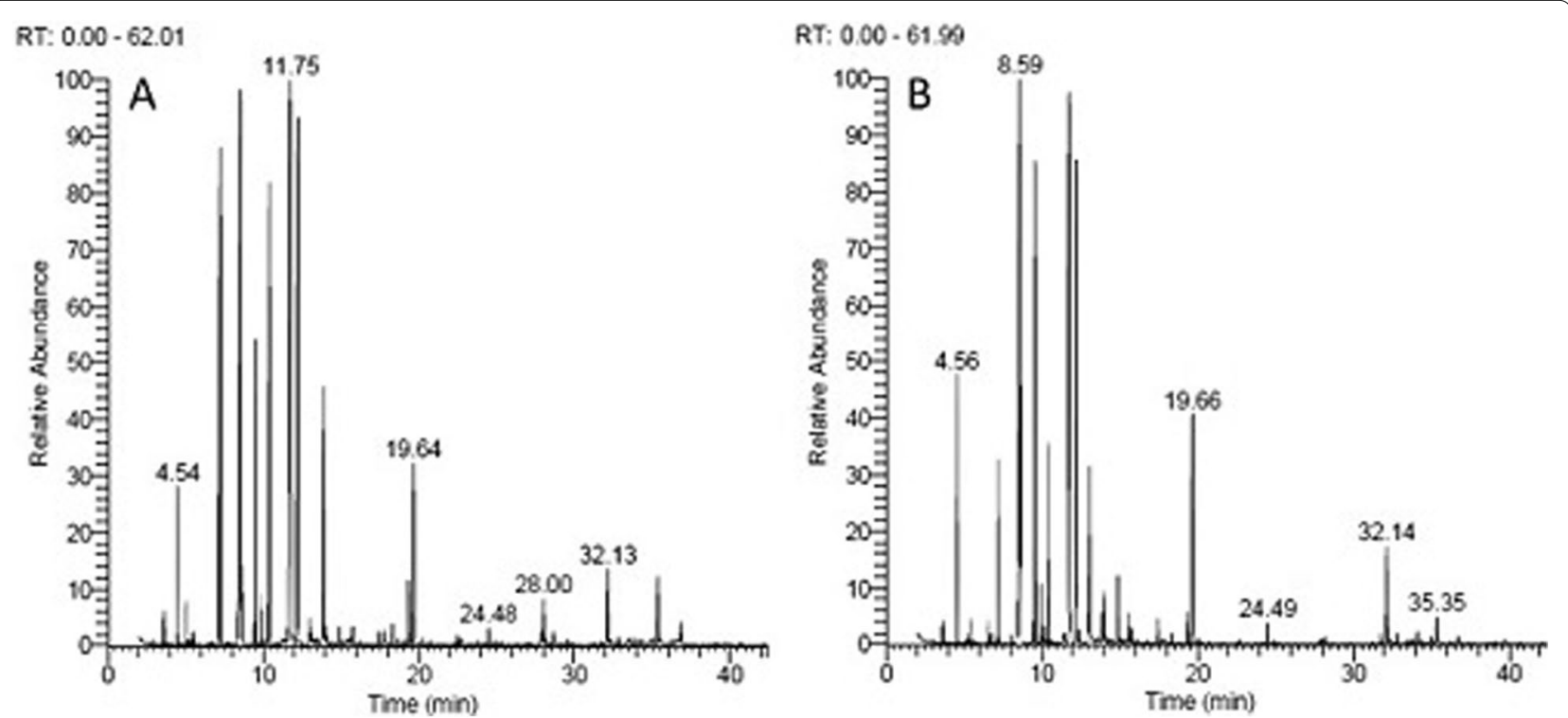

Fig. 5 GC-MS total chromatogram for the volatile oil of the two fragrantissima wild accessions W1-3 and W 4-1 

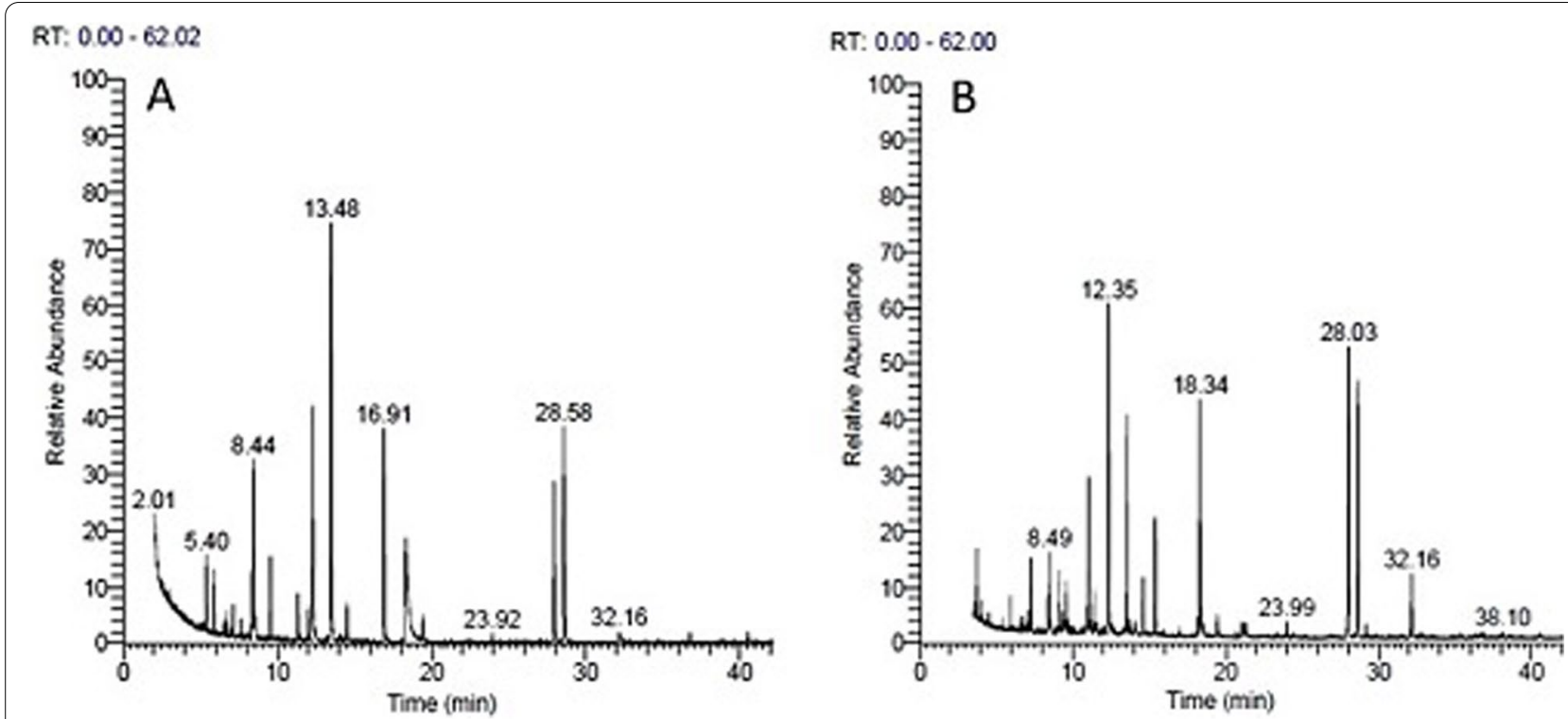

Fig. 6 GC-MS total chromatogram for the volatile oil of the in vitro regenerated genotypes R1-3 and R 4-1 of the wild accessions W1-3 and W 4-1

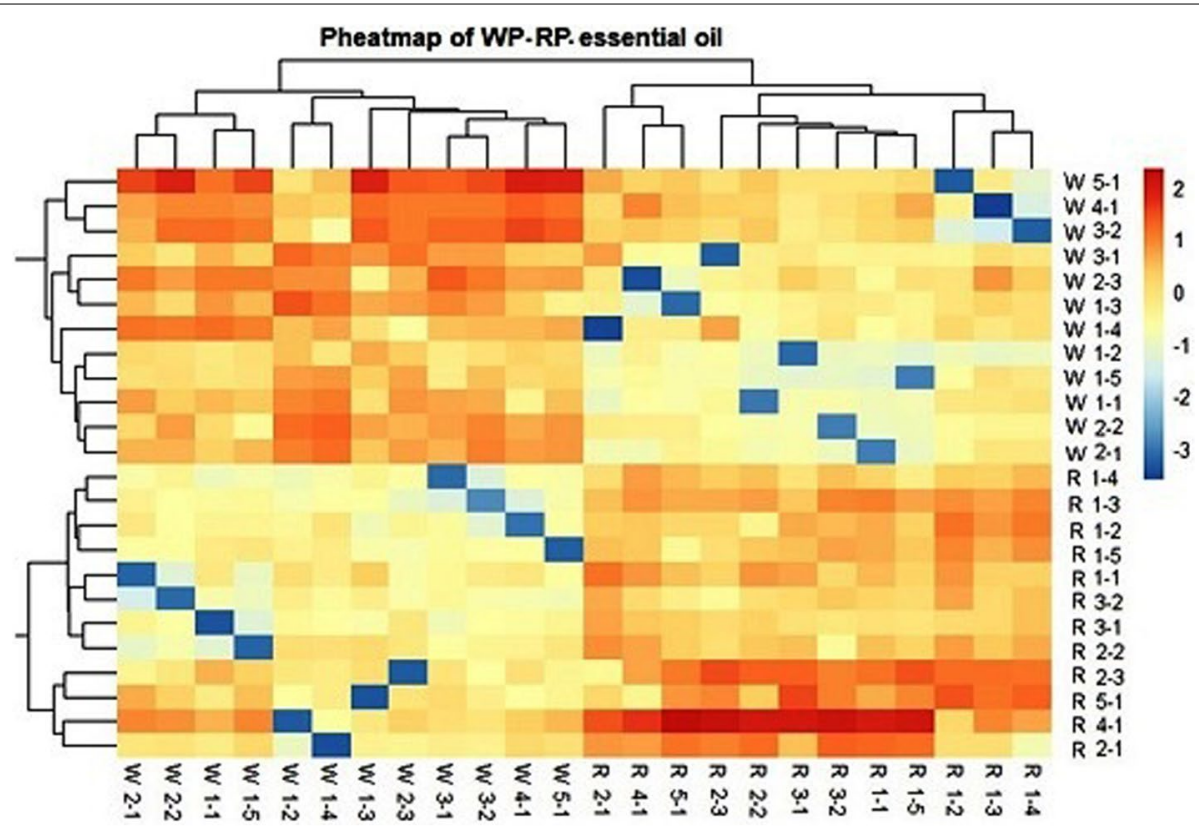

Fig. 7 Heatmap illustrating the relatedness of the wild accessions and regenerated genotypes based on the variation of chemical constituents of the essential oil

similarity of the wild accessions to each other and the similarity of the regenerated genotypes to each other. On the other hand, some resemblance among wild accessions and regenerated genotypes is also indicated by the red color in most cells of the heatmap illustrating resemblance between wild accessions and regenerated genotypes (Fig. 7). Meanwhile, evident divergence was indicated by the blue color in 12 cells indicating divergence between every 12 wild accessions and 12 regenerated plants, However, no blue color was recorded for any wild accessions and their in vitro regenerated genotype indicating that the genotype of the wild accessions is more preserved in its regenerants than other in vitro regenerated plants. 


\section{Correlation of essential oil constituents and morphological traits and ISSR fingerprinting}

The correlation coefficients between the chemical components of the essential oil and the ten morphological traits for the 12 accessions of $A$. fragrantissima, as two variables calculated by $\mathrm{R}$-software are shown in Fig. 8. The correlation coefficients are colored blue for positive correlations and colored red for negative correlations. In general, few morphological traits are correlated with particular compounds of the essential oil. Similarly, the Pearson correlation coefficient values between the ISSR fingerprinting markers and the volatile oil components in the wild accessions of $A$. fragrantissima are given in the supplementary Table 1A and the Pearson correlation coefficients of the ISSR markers and the volatile oil components, in the regenerated genotypes are given in the supplementary Table 1B. In general, few significant correlations were evident. For wild accessions, almost all monomorphic ISSR bands showed no correlation with oil components. As for regenerated genotypes, there is only one unique band that has a correlation with dodecane but piperitone showed correlation with 35 bands including 15 are +ve correlations and 20 -ve correlations. Artimisia ketone showed 14 correlations, including nine -ve and five +ve. Dodecane has 12 correlations, eight are -ve and four are + ve but only negative correlations were present in all genotypes derived from wild accession of site 1 .

\section{Discussion}

The foregoing data indicated that the analysis of ISSR fingerprinting revealed genetic variation between the wild accessions and their in vitro regenerated genotypes which represents limited genotypic fidelity of the in vitro propagated genotypes to their mother accessions. However, the differences between wild accessions were inherited to the regenerated genotypes as in vitro raised plants of the same site are closer to each other compared to genotypes regenerated from different sites. Some authors reported true-to-mother plant ISSR fingerprinting in the regenerated plants. Examples include Rauwolfia tetraphylla, [8], Hedychium coronarium [7], Helianthus verticillatus [9], and the blackberry [10]. However, genetic variations of plants in tissue cultures are well reported. Hamouda et al. [40] reported RAPD band pattern differences between mother plants and in vitro grown Silybum marianum genotypes indicating the existence of genetic variation. Meanwhile, Rady et al. [41] acknowledged inadequate genetic fidelity of in vitro raised $S$. marianum genotypes and Badr et al. [26] reported polymorphism in the $A$. fragrantissima plants. In the current study, the Euclidean distance UPGMA-CAP tree differentiated all wild accessions from the regenerated genotypes as two different groups. In each group, plants representing different sites were differentiated based on the analysis of ISSR polymorphism with the exceptions of the clusters from the two samples representing site 4 and site 5 respectively. However, in this tree, the regenerated genotypes are relatively more diverse compared to

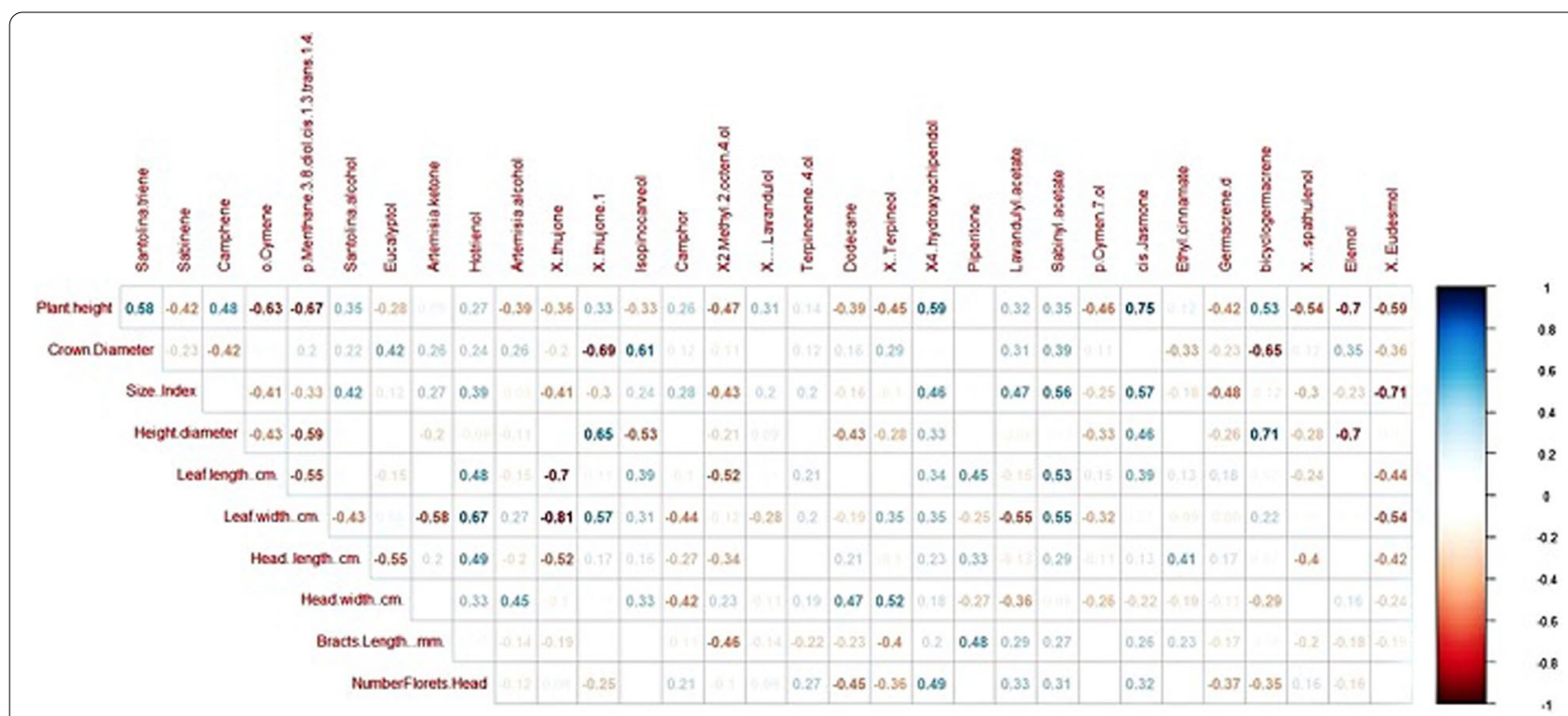

Fig. 8 The correlation coefficients between the chemical components of the essential oils and the ten morphological traits for the 12 accessions of A. fragrantissima as two variables calculated by R-software 
their wild mother accessions. The genetic divergence of the regenerated genotypes is clearly illustrated in the PCA scatter diagram. The genotypic differentiation of the examined wild accessions may be due to spatial and environmental differences in the sites from which the plants were collected [27], but the genetic variation between the in vitro raised genotypes may have been elicited by conditions and chemicals used for in vitro culture.

The GC-MS analysis of individual wild accessions of A. fragrantissima produced a wide 31 compounds in the volatile oil GC-MS chromatogram. In this respect, a comparative study of the volatile constituents of the essential oils of dried A. fragrantissima cultivated in Saudi Arabia and Egypt extracted using hydro-distillation and solid-phase microextraction (SPME) also revealed 31 compounds. Santolina alcohol, artemisia ketone, $\alpha$-thujone, 4(10)-thujen-3-ol, $\beta$-thujone, were the predominant components in both extracts, with quantities varying with extraction method. The identified compounds include oil terpene hydrocarbons (aliphatic and cyclic) and their corresponding oxygenated isoprenoid derivatives and analogs. Most of the major volatile oil constituents identified in the present study were previously reported. Santolina alcohol (12.5-21.2\%), artemisia ketone (13.2-23.8\%), alpha-thujone (25.5-36.5\%), constituted the main compounds for material from Sinai [42]. Santolina alcohol, artemisia alcohol, artemisia ketone, cis-thujone, and trans-thujone were also major constituents in the hydro-distilled oil and solvent extract of A. fragrantissima material from other parts in Egypt [28]. Artemisia ketone represented $49.53 \%$ and camphor $14.73 \%$ of essential oil from the leaves of $A$. fragrantissima growing wild in Yemen and the components of the essential were recommended for treatment of colon cancer [43]. Moreover, in the present study, some chemical compounds present in the wild accessions only and missing from the in vitro regenerated plants like santolina triene, sabinene, p-menthane-3,8-diol,cis-1,3,trans-1,4-, beta-thujone, isopinocarveol, 2-Methyl-2-octen-4-ol, $\beta$-eudesmol, and spathulenol, others present only in the in vitro plants such as limonene, 1-borneol, and dotriacontane. Moreover, piperitone was slightly reduced in regenerated plants derived from accessions of wild populations 1 and was only increased in the regenerated plants from W1-4 and W1-5. In the meantime, dodecane was generally increased. However, the values of the chemical compounds are given as a percentage and an increase of some compounds may be the result of a decrease in other compounds. The increase in the latter two compounds in the regenerated plants is congruent with their synthesis in the leaves of plants at the vegetative growth stage. At maturity, the vegetative leaves are often old and terminal branches and flowers are often the site in which volatile oil are synthesized. In vitro the plants were harvested before flowering and fruiting stage.

It has been reported that yield and chemical components in medicinal wild plants may be influenced by climate, soil, elevation, and topography, and their interaction [44-47]. In addition, the physiological situation of plants, time of collection, and different ecological conditions have a great effect on both the quantity and quality of essential metabolites in medicinal and aromatic plants in vitro and in vivo [48]. In Silybum marianum, Shokrpour et al. [17] showed that morphological traits, such as seed weight, flowering date, and plant height variation were determined by informative AFLP markers and qualitative and quantitative properties of the essential oil. In the $A$. fragrantissima unique bands were found associated with larger plant size and seed yield as well as better vigor [26]. In the current study, the environmental, soil, and other external factors prevailing in the study area have been minimized by a collection of wild accession of similar size and age at the same time. These precautions are important criteria for selecting accessions and sites for conservation and sustainable commercial use of $A$. fragrantissima as an important medicinal plant.

Gharib [49] found that the relative amounts of the major components of the essential oil of the Pelargonium nervosum regenerated shoots, were different from those present in the partially differentiated callus and parent plant and only citral was the main oil components present in all cultures [49]. The GC-MS chromatogram of essential oils of dried aerial parts of Salvia sclarea L. plants, regenerated in vitro and reproduced from seeds, were similar, although the yield of essential oil from in vitro plants was lower than the oil yield isolated from in vivo S. sclarea plants [50]. In Teucrium scorodonia L. ssp. scorodonia, the components of the essential oil from the micropropagated plants and the seed-derived plants were qualitatively similar but, quantitative differences were evident [51]. In the current study, acclimatized in vitro gown regenerants of the same mother plants were of similar size and age and grown under the same conditions. In the regenerated genotypes of $A$. fragrantissima, a total of 24 volatile compounds were detected while in the wild accessions, 31 compounds were detected in the GC-MS chromatogram. This variation is due to is the fact that mature wild plants and the in vitro propagated plants were harvested at different developmental. Although largely species specific, volatile oil components amount, and types vary with the age of the plant and the environmental condition. Future optimization of growth conditions like temperature or culture age and elicitors additions would help achieve the best in vitro conditions 
for metabolite production. Four major compounds are common to both wild and regenerated plants, these are artemisia ketone, alpha-thujone, dodecane, piperitone. DNA fingerprinting and essential oil content variation was also common in callus-derived regenerants of Curcuma longa and was attributed to soma-clonal variations in derived regenerants [52]. In the in vitro grown genotypes, chemotype-specific markers are less likely reported in Silybum marianum by Shokrpour et al. [17] and in Thymus vulgaris by György et al. [18]. The latter authors assumed that no chemotype-specific markers can be found without sequence information. Under plant morphogenesis, DNA methylation and histone modifications are very susceptible to those in vitro environmental conditions which may induce genetic and epigenetic variability in the regenerated plants [53].

\section{Conclusions}

The genetic diversity analyses using clustering and principal component analyses generally differentiated the mother wild accessions of $A$. fragrantissima from their regenerated genotypes. The resemblance of wild accessions from different sites and the regenerated genotypes indicates that genetic variation of wild accessions was inherited to their in vitro propagated genotypes. The number of volatile oil compounds in the wild $A$. fragrantissima accessions was 31 compounds while in the in vitro propagated plants only 24 compounds were detected. The amount of volatile oil is much greater in the wild accessions compared to regenerated plants. Four major compounds are common to both wild and regenerated plants, but considerable variation in the types and amounts of compounds was evident among the wild accessions and their in vitro regenerated genotypes. In vitro conditions elicited higher genetic variation that may be associated with diversity in essential oil components, but no particular correlations are persistent between ISSR markers and volatile oil components.

\begin{abstract}
Abbreviations
ISSR: Inter simple sequence repeats; SCOT: Start codon targeted polymorphism; RAPD: Random amplified polymorphic DNA; SRAP: Sequence-related amplified polymorphism; GC-MS: Gas chromatography-mass spectrometry; PCR: Polymerase chain reaction; MS medium: Murashige and Skoog medium; BA: Benzyl adenine; NAA: 1-Naphthaleneacetic acid; CAP: Community Analysis Package-5; The PAST: Paleontological Statistics; UPGMA: Unweighted Pair Group Method with Arithmetic Mean; PCA: Principal coordinates analysis; pr: Primer; W: Wild accessions; R: Regenerated genotypes.
\end{abstract}

\section{Supplementary Information}

The online version contains supplementary material available at https://doi. org/10.1186/s43141-021-00267-3.

Additional file 1.

\section{Acknowledgements}

The authors are grateful to the Science, Technology \& Innovation Funding Authority (STDF) of Egypt for supporting this work. Also, We appreciate the help of Prof. Emad Farahat of Helwan University for conducting the Pearson correlations and Faten $Y$. Ellmouni of Fayoum University for conducting the $R$ analysis

\section{Authors' contributions}

AB: Work proposal, supervision, data validation, writing-editing. HHE: sample collection, writing the first draft, reviewing. MS: work design, reviewing revision. MMF: Chemical data analysis, writing the first draft. MMH: methodology, data scoring, and analysis. EE: samples collection, methodology. HIS: Methodology, data analysis, first draft, reviewing. The author(s) read and approved the final manuscript.

\section{Funding}

This work was funded by a Science, Technology \& Innovation Funding Authority (STDF) of Egypt Project ID 4218 titled: Development of reference genetic fingerprints, and biotechnology-based production of pharmaceutically bioactive substances of some threatened Egyptian medicinal plants.

\section{Availability of data and materials}

Not applicable.

\section{Declarations}

Ethics approval and consent to participate

Not applicable.

\section{Consent for publication}

Not applicable.

\section{Competing interests}

The authors declare that they have no competing interests.

\section{Author details}

${ }^{1}$ Botany and Microbiology Department, Faculty of Science, Helwan University, Cairo 117900, Egypt. ${ }^{2}$ Department of Biological Sciences and Geology, Faculty of Education, Ain Shams University, Cairo 11341, Egypt. ${ }^{3}$ Department of Plant Biotechnology, National Research Center, Cairo, Egypt. ${ }^{4}$ Department of Phytochemistry and Plant Systematics, National Research Centre, Cairo, Egypt.

${ }^{5}$ Botany and Microbiology Department, Faculty of Science, Tanta University, Tanta 31527, Egypt.

Received: 12 July 2021 Accepted: 8 October 2021

Published online: 25 October 2021

\section{References}

1. Ayyad M (2003) Case studies in the conservation of biodiversity: degradation and threats. J Arid Environ 54(1):165-182

2. Edwards R (2004) No remedy in sight for herbal ransack. New Sci 181(2429):10-11

3. Badr A et al (2014) Role of biotechnology in conservation and sustainable use of medicinal plants in the arid regions. Recent Prog Med Plants 39:317-333

4. Butiuc-Keul A, Farkas A, Cristea V (2016) Genetic stability assessment of in vitro plants by molecular markers. Stud Univ Babeş-Bolyai Biol 61(1):107-114

5. Cardoso JC, Gerald LTS, da Silva JAT (2018) Micropropagation in the twenty-first century. In: Plant cell culture protocols, pp 17-46

6. Gantait S, Debnath S, Ali MN (2014) Genomic profile of the plants with pharmaceutical value. 3 Biotech 4(6):563-578

7. Behera S et al (2019) Genetic and biochemical fidelity of in vitro regenerated plants, p 134

8. Rohela GK et al (2019) Indirect regeneration and assessment of genetic fidelity of acclimated plantlets by SCOT, ISSR, and RAPD markers in Rauwolfia tetraphylla L.: an endangered medicinal plant. BioMed Res Int 2019:3698742 
9. Nowakowska M et al (2020) In vitro propagation of an endangered Helianthus verticillatus by axillary bud proliferation. Plants 9(6):712

10. Borsai $O$ et al (2020) Evaluation of genetic fidelity of in vitro-propagated blackberry plants using RAPD and SRAP molecular markers. Hortic Sci 47(1):21-27

11. Duncan R (1996) Tissue culture-induced variation and crop improvement. Adv Agron 58:201-240

12. Leva A, Rinaldi LMR (2017) Somaclonal variation. In: Thomas B, Murray BG, Murphy DJ (eds) Encyclopedia of applied plant sciences (second edition). Academic, Oxford, pp 468-473

13. Yakovlev IA et al (2011) Differential gene expression related to an epigenetic memory affecting climatic adaptation in Norway spruce. Plant Sci 180(1):132-139

14. Springer NM (2013) Epigenetics and crop improvement. Trends Genet 29(4):241-247

15. Zarreen B, Saifullah K, Huma R (2017) Analysis of genetic fidelity of wild type and in vitro regenerated aloevera plants through RAPD and ISSR molecular markers. Int J Biot Bioeng 3(8):259-267

16. Kour B et al (2014) In vitro mass multiplication and assessment of genetic stability of in vitro raised Artemisia absinthium L. plants using ISSR and SSAP molecular markers. Adv Bot 2014:727020

17. Shokrpour M et al (2008) Analysis of morphologic association, phytochemical and AFLP markers in milk thistle (Silybum marianum L.). IJMAPR 24(3):278-292

18. György Z, Incze N, Pluhár Z (2020) Differentiating Thymus vulgaris chemotypes with ISSR molecular markers. Biochem Syst Ecol 92:104118

19. Patocka J, Navratilova Z (2019) Achillea fragrantissima: pharmacology review. Clin Oncol 4:1601

20. Batanouny K et al (1999) Wild medicinal plants in Egypt: an inventory to support conservation and sustainable use. Academy of Scientific Research and Technology (Egypt) \& IUCN Unpublished Report: [List of some native medicinal plants in Egypt] (Vol. 154). The Palm press, Cairo.

21. Barel S, Yashphe J (1989) Effect of the essential oil from Achillea fragrantissima on Escherichia coli cells. Curr Microbiol 19(6):337-341

22. Alsohaili S (2018) Seasonal variation in the chemical composition and antimicrobial activity of essential oil extracted from Achillea fragrantissima grown in northern-eastern Jordanian desert. J Essent Oil Bear Plants 21(1):139-145

23. Soltan MM, Zaki AK (2009) Antiviral screening of forty-two Egyptian medicinal plants. J Ethnopharmacol 126(1):102-107

24. Elmann A et al (2011) Anti-neuroinflammatory effects of the extract of Achillea fragrantissima. BMC Complement Altern Med 11(1):1-10

25. Hamed AR et al (2016) Potency of extracts from selected Egyptian plants as inducers of the Nrf2-dependent chemopreventive enzyme NQO1.J Nat Med 70(3):683-688

26. Badr A et al (2017) Genetic diversity of Achillea fragrantissima in Egypt inferred from phenotypic variations and ISSR markers associated with traits of plant size and seed yield. Plant Genet Resour 15(3):239-247

27. El-Shazly HH et al (2020) Genetic diversity and population structure of the medicinal plant Achillea fragrantissima (Forssk.) Sch. Bip. in the mountains of South Sinai, Egypt. Plant Gene 21:100212

28. El-Shazly A, Hafez S, Wink M (2004) Comparative study of the essential oils and extracts of Achillea fragrantissima (Forssk.) Sch. Bip. and Achillea santolina L.(Asteraceae) from Egypt. Pharmazie 59(3):226-230

29. Zeedan G et al (2014) Antimicrobial, antiviral activity and GC-MS analysis of essential oil extracted from Achillea fragrantissima plant growing in Sinai Peninsula. Egypt J Microb Biochem Technol S 8(6):1-7

30. Farouk A et al (2019) Comparative study for the volatile constituents and the antioxidant activity of the essential oils of dried Achillea fragrantissima cultivated in Madinah Monawara, Saudi Arabia and Egypt. Int J Food Prop 22(1):395-404
31. Murashige T, Skoog F (1962) A revised medium for rapid growth and bio assays with tobacco tissue cultures. Physiol Plant 15(3):473-497

32. Seaby R, Henderson P (2007) Community Analysis Package 4.0: searching for structure in community data. PISCES Conservation Ltd., Lymington

33. Ward JH Jr (1963) Hierarchical grouping to optimize an objective function. J Am Stat Assoc 58(301):236-244

34. Hammer O, Harper DA, Ryan PD (2001) Palaeontological statistics software package for education and data analysis. Palaeontol Electron 4(9)

35. Wickham H (2016) ggplot2-elegant graphics for data analysis. Springer International Publishing, Cham

36. Kassambara A (2020) ggpubr:"ggplot2" based publication ready plots (version 0.3. 0) [Computer software]

37. Paradis E (2012) Analysis of phylogenetics and evolution with R, vol 2. New York: Springer

38. Kassambara A, Mundt F (2017) Package 'factoextra'. Extract and visualize the results of multivariate data analyses, $\mathrm{p} 76$

39. RStudio Team U (2015) RStudio: integrated development for R, vol 42 . RStudio, Inc., Boston, p 14 http://www.rstudio.com

40. Hamouda M (2019) Molecular analysis of genetic diversity in population of Silybum marianum (L.) Gaertn in Egypt. J Genet Eng Biotechnol 17(1):1-9

41. Rady M, Saker M, Matter M (2018) In vitro culture, transformation and genetic fidelity of Milk Thistle. J Genet Eng Biotechnol 16(2):563-572

42. Fleisher Z, Fleisher A (1993) Volatiles of Achillea fragrantissima (Forssk.) Sch. Bip. Aromatic plants of the holy land and the Sinai. Part XI. J Essent Oil Res 5(2):211-214

43. Mansi I et al (2019) Chemical composition and biological activity of the essential oil isolated from the leaves of Achillea fragrantissima growing wild in Yemen. Pharmacogn J 11(5):1077-1081

44. Ložienè $K$, Venskutonis P (2005) Influence of environmental and genetic factors on the stability of essential oil composition of Thymus pulegioides. Biochem Syst Ecol 33(5):517-525

45. Rahimmalek M et al (2009) Genetic variability and geographic differentiation in Thymus daenensis subsp. daenensis, an endangered medicinal plant, as revealed by inter simple sequence repeat (ISSR) markers. Biochem Genet 47(11-12):831

46. Sampaio BL, Da Costa FB (2018) Influence of abiotic environmental factors on the main constituents of the volatile oils of Tithonia diversifolia. Rev Bras Farmacogn 28:135-144

47. Akula R, Ravishankar GA (2011) Influence of abiotic stress signals on secondary metabolites in plants. Plant Signal Behav 6(11):1720-1731

48. Ibañez J, Usubillaga A (2006) The essential oil of Espeletia schultzii of different altitudinal populations. Flavour Frag J 21 (2):286-289

49. Gharib F (2005) Changes in regeneration and oil accumulation of Pelargonium nervosum under various culture conditions. J Biol Sci 5(5):670-677

50. Kuźma $Ł$ et al (2009) Chemical composition and biological activities of essential oil from Salvia sclarea plants regenerated in vitro. Molecules 14(4):1438-1447

51. Makowczyńska J et al (2016) In vitro propagation, DNA content and essential oil composition of Teucrium scorodonia L. ssp. scorodonia. PCTOC 127(1):1-13

52. Kuanar A et al (2012) Nuclear DNA, DNA finger printing and essential oil content variation in callus derived regenerants of Curcuma longa $\mathrm{L}$. Nucleus 55(2):101-106

53. Us-Camas $R$ et al (2014) In vitro culture: an epigenetic challenge for plants. PCTOC 118(2):187-201

\section{Publisher's Note}

Springer Nature remains neutral with regard to jurisdictional claims in published maps and institutional affiliations. 